\title{
INVESTIGACIONES EN QUILLAGUA: DIFUSIÓN DEL CONOCIMIENTO ARQUEOLÓGICO Y PROTECCIÓN DEL PATRIMONIO CULTURAL
}

\author{
RESEARCH IN QUILLAGUA: DIFFUSION OF ARCHAEOLOGICAL \\ KNOWLEDGE AND PROTECTION OF CULTURAL HERITAGE
}

\author{
Carlos Carrasco*, Carolina Agüero*, Patricia Ayala**, Mauricio Uribe*** \\ y Bárbara Cases**
}

\begin{abstract}
Se presenta la síntesis de la experiencia obtenida a través de dos proyectos de investigación financiados por FONDECYT (1950071 y 1990168). Estos proyectos motivaron la preocupación de sus integrantes por dar a conocer a la comunidad de Quillagua en qué consiste la labor arqueológica y por difundir los resultados obtenidos más allá de un ámbito puramente científico. Esta experiencia continúa una línea de trabajo que se viene realizando desde hace varios años en el Loa Superior en la cual se pone énfasis en mantener una relación fluida entre arqueólogos y comunidades. Esta relación ha permitido que la comunidad denuncie situaciones de saqueo y destrucción de sitios arqueológicos, pudiéndose de esta manera dar protección efectiva al patrimonio cultural

Palabras claves: Patrimonio cultural, investigación, difusión, comunidades actuales.
\end{abstract}

A synthesis of the experience of two research projects funded by FONDECYT(1950071 and 1990168) is presented. While conducting these projects, the researchers where interested in presenting to the community of Quillagua what archaeological research is all about beyond the scientific audience. This experience continues a line of work-which has been conducted for several years in the Upper Loa region- emphasises to maintain a fluid relationship between archaeologists and local communities. This relationship has led the communities to report cases of looting and destruction of archaeological sites, thus allowing to protect more effectively the cultural heritage of the region.

Key words: Archaeological research, community, protection of cultural heritage.

La localidad de Quillagua se sitúa en plena región desértica del norte de Chile justo en el límite entre la I y II Región, aproximadamente a 70 km de la desembocadura del río Loa, cuyas aguas en su curso inferior riegan el valle. En él crece una gran cantidad de algarrobos y chañares y se desarrollan algunas actividades agrícolas orientadas al mercado local y al cultivo de la alfalfa. Dichas actividades se encuentran hoy altamente mermadas y deterioradas debido a la creciente contaminación a la que se ha expuesto el río Loa por parte de la minería de cobre y salitre que se desarrolla aguas arriba. Cabe mencionar, además, la pérdida de los derechos de aguas de los comuneros de Quillagua en favor de una de estas empresas mineras. Sin embargo, también existen en la localidad algunas familias dedicadas al pastoreo de pequeños rebaños de camélidos combinando de esta manera sus actividades económicas.

Los estudios arqueológicos en Quillagua se remontan hacia finales del siglo XIX y principios del $\mathrm{XX}$, centrándose principalmente en la antropología física y el arte rupestre (Fonck 1912; Vergara 1897, 1901, 1905, citados por Gallardo et al. 1993a). En forma posterior a estos trabajos un primer panorama histórico-cultural fue propuesto por Latcham (1933 y 1938), destacando la excavación de sitios claves como los cementerios Poniente, Oriente y Ancachi, los cuales ya en ese entonces se hallaban saqueados (Gallardo et al. 1993a y b).

\footnotetext{
* Instituto de Investigaciones Arqueológicas y Museo R.P. Gustavo Le Paige s.j., Universidad Católica del Norte, San Pedro de Atacama, Chile.c_acg@yahoo.com; mcagüero@netline.cl

** Programa Magíster en Antropología Universidad de Tarapacá, Arica, Chile y Universidad Católica del Norte, San Pedro de Atacama, Chile. payala_rocabado@hotmail.com; bcases@ucn.cl

*** Departamento de Antropología, Universidad de Chile, Santiago, Chile. mur@uchile.cl; mur_cl@yahoo.com
} 
A partir de la década de 1980 otros investigadores han trabajado en Quillagua ampliando y/o ajustando de manera sistemática y sintética aquella secuencia histórico-cultural, entre éstos se encuentran Cervellino y Téllez (1980), Núñez (1965, 1968, 1978), Gallardo y colaboradores (Gallardo et al. 1993a y b), además de los autores de este artículo (Agüero 1995; Agüero et al. 1997, 1999, 2001). Las primeras investigaciones financiadas por FONDECYT fueron las de Gallardo y colaboradores (FONDECYT 0198/91). Posteriormente, un equipo compuesto básicamente por quienes escriben, ha desarrollado en Quillagua dos proyectos de investigación: FONDECYT 1950071 y 1990168, que han tratado de los períodos Intermedio Tardío y Formativo, respectivamente.

En el primero de éstos denominado "Variabilidad textil durante el Período Intermedio Tardío en el valle de Quillagua: Una aproximación a la etnicidad", se buscaba llegar a determinar ciertos indicadores de identidad cultural a partir del trabajo de materiales textiles que se pudieran obtener en dos cementerios muy saqueados de la localidad $^{1}$.

Las investigaciones arqueológicas llevadas a cabo en Quillagua hasta antes de este proyecto eran coincidentes en describir a esta localidad como un área marginal en torno a los desarrollos culturales del Norte Grande de Chile como lo son Arica-PicaTarapacá y Loa-San Pedro (Odone 1995), aunque al mismo tiempo se percibía el importante detalle de que durante el Período Intermedio Tardío habrían coexistido en Quillagua grupos humanos vinculados a las distintas tradiciones culturales de estos territorios, definiendo así un área de "frontera" en cuanto este espacio favorece el contacto, el intercambio y la expresión étnica (Agüero et al. 1997, 1999).

Dichas tradiciones habían sido representadas y caracterizadas fundamentalmente por el material cerámico recuperado en los cementerios dados a conocer por Latcham $(1933,1938)$ correspondientes a los cementerios Oriente y Oriente Alto (Qui-01 y Qui-02) y al cementerio Poniente (Qui-03), y al sitio habitacional denominado Aldea La Capilla (Qui-04) (Agüero et al. 1997, 1999). Latcham habría identificado por primera vez la presencia de materiales culturales propios de la región tarapaqueña en los cementerios al oriente del Loa, y en el cementerio Poniente y Aldea La
Capilla evidencias culturales vistas en territorio atacameño. Esto también fue confirmado por Núñez años más tarde con nuevos argumentos (Núñez 1968, 1978, citado por Agüero et al. 1997, 1999).

Bajo esta perspectiva se postuló que otros restos materiales, tales como los textiles, también podían manifestar la coexistencia de estas distintas tradiciones culturales, por lo que Quillagua podría ser un área interesante para abordar el problema de las identidades culturales a través de un estudio experimental. De este modo, y considerando como antecedente el hecho que actualmente los tejidos son utilizados por poblaciones andinas como un medio de autoidentificación grupal en momentos de contacto cultural, igualmente podrían servir para detectar estas situaciones de etnicidad en los contextos arqueológicos como los del Intermedio Tardío.

El objetivo del estudio también se centró en tratar de entender la dinámica diacrónica de estos encuentros culturales y relaciones intergrupales, en un contexto más amplio que a su vez explicara cómo la localidad de Quillagua se comporta como un espacio de "frontera" entre los territorios y tradiciones culturales de Tarapacá y Atacama, las que están bastante bien representadas en el registro arqueológico de Quillagua (Agüero et al. 1997, 1999).

Para desarrollar esta investigación se excavaron los sitios ya mencionados -algunos de los cuales ya habían sido trabajados por Latcham y que se encontraban sumamente saqueados- en conjunto con un estudio de colecciones de referencia de las regiones culturales representadas en Quillagua (Arica, Pica-Tarapacá, Loa Superior y San Pedro de Atacama). Por otra parte, se consideró los indicadores histórico-culturales derivados de la cerámica.

Como consecuencia de esta investigación, se logró crear una secuencia histórico-cultural a partir de los materiales fragmentados que alguna vez formaron parte de las ofrendas de los cementerios saqueados de Quillagua, con lo que se concluyó que esta "zona de frontera" entre los territorios de Tarapacá y Atacama mostraba desde los inicios del Período Intermedio Tardío un dominio prácticamente total por parte de poblaciones atacameñas, pero en un momento inmediatamente posterior, se habría producido una significativa penetración de 
poblaciones tarapaqueñas en el oasis (Agüero et al. 1997, 1999).

De este modo, mientras la cerámica mantuvo una identidad casi monolítica, caracterizando a uno y otro grupo, los textiles fueron los que permitieron inferir situaciones derivadas del contacto, introduciendo elementos formales y decorativos del estilo tarapaqueño, sobre un sustrato estructural, y más bien técnico, del estilo atacameño. Así, "la vestimenta de los individuos se convirtió en el instrumento de diálogo, que admitió y negoció las diferencias, sin la necesidad de la violencia física" (Agüero et al. 1999: 192-193).

El segundo proyecto (FONDECYT 1990168) se tituló "Tejidos, alfarería y cementerios: El Período Intermedio Temprano desde Quillagua, Loa Inferior". En él se intentó realizar una profundización temporal de los resultados de las investigaciones desarrolladas en el proyecto anterior.

En efecto, esta investigación aspiró lograr una identificación y caracterización de las diferentes expresiones formativas asignables a distintas regiones culturales y zonas geográficas del norte de Chile presentes en el valle de Quillagua, así como también definir las expresiones culturales locales del período y las posibles relaciones establecidas entre las diferentes poblaciones formativas al interior de la localidad. Surge como consecuencia del proyecto anteriormente descrito, al trasladar en el tiempo la pregunta sobre las identidades y situaciones detectadas durante el Período Intermedio Tardío hasta el Período Intermedio Temprano o Formativo (Agüero et al. 1997, 1999). En general, en la identificación de las distintas regiones culturales se han utilizado los conjuntos cerámicos y textiles del registro material ${ }^{2}$.

Para el desarrollo de esta investigación se han trabajado materiales ya excavados y depositados en distintos museos y colecciones correspondientes a tradiciones culturales de las áreas geográficas de Arica-Tarapacá, Loa-San Pedro de Atacama y Altiplano de Bolivia. Además se han realizado excavaciones en cementerios y sitios habitacionales.

Las excavaciones se llevaron a cabo en los sitios Qui-84 y Qui-89 correspondiendo el primero a un cementerio de fosas y el segundo a un sitio ceremonial de túmulos de características similares a aquellos de Arica y la costa desértica, y que determinan a la fase Alto Ramírez. Ambos sitios han sido fechados entre 700 y 500 años a.C. y sus contextos nos refieren a expresiones culturales tanto de la región del Loa Superior, como locales, asî como un débil componente tarapaqueño, lo que ha sido registrado básicamente a través de las tecnologías cerámicas (Agüero et al. 2001). En términos generales, se logró un completo registro de la materialidad tanto de las colecciones de referencia que se han revisado, así como de los materiales que han sido rescatados de los sitios trabajados, además de fechados absolutos mediante TL.

\section{El Saqueo de los Sitios y la Protección del Patrimonio Cultural}

Uno de los problemas que ha debido enfrentar nuestro equipo de trabajo, y quizás el más grave de todos, es el saqueo de los sitios. Este hecho es muy recurrente en la localidad y no discrimina sitios. Es decir, la mayoría de los yacimientos, por no decir todos, sean estos habitacionales, cementerios o ceremoniales, presentan un cierto grado de alteración producida por esta depredación.

Esta práctica va desde pequeños pozos de distintas formas y tamaños hasta casos aberrantes de enormes fosas, en las cuales posiblemente se han utilizado explosivos para su realización.

Respecto de lo anterior, los casos de los cementerios Oriente (Qui-01), Oriente Alto (Qui-02) y Poniente (Qui-03), objetos de estudio del primer proyecto de este equipo (FONDECYT 1950071), son los que han resultado más dañados, detectándose incluso nombres personales escritos en las pendientes de emplazamiento de los sitios con los huesos humanos largos extraídos de los cementerios.

En estos emplazamientos es enorme la cantidad de material cultural fragmentado que ha quedado esparcido, así como la formación de depresiones y montículos generados por la ejecución de pozos. Estos saqueos se han venido realizando de manera sistemática o intermitentemente desde hace muchos años. Al menos en una de las cuadrículas de excavación del cementerio Oriente o Qui-01, a una profundidad de casi $1,8 \mathrm{~m}$, se rescató una hoja de periódico fechado en la década de 1920. Del mismo modo Latcham (citado por Gallardo et al. 1993a y b), menciona que su trabajo en Ancachi lo realizó sobre el sitio ya saqueado, por lo que este tipo de eventos escapa absolutamente a las responsabilidades de los arqueólogos. 
En la mayoría de los sitios, sobre todo en los cementerios, los saqueos corresponden a pozos de tipo circular en el que se ha dejado material cultural fracturado y esparcido alrededor de los mismos.

Pero no sólo los saqueos, planificados o no, son los que comprometen la disturbación e integridad de los sitios arqueológicos de Quillagua, sino que también hay otras actividades que, no teniendo como objetivo este propósito, generan graves daños al patrimonio. En este sentido, los trabajos camineros y otros proyectos de desarrollo también han provocado alteraciones importantes.

$\mathrm{Al}$ respecto, nuestro equipo ha llevado a cabo labores de rescate, entre las actividades de investigación en terreno, alertados por los propios miembros de la comunidad quillagüina (principalmente por don Porfirio Vega, conocido miembro de la comunidad) sobre la exposición de materiales culturales generados por obras civiles realizadas en la localidad por distintas empresas.

En efecto, una máquina motoniveladora que realizaba trabajos de mantención en el camino de acceso a Quillagua desde la Ruta 5 Norte destruyó un sitio arqueológico ubicado en la ladera del cerro, dejando al descubierto un contexto mortuorio perteneciente al sitio Qui-81. De este yacimiento rescatamos lo que quedaba de los restos óseos de un individuo adulto y un niño. De acuerdo al tipo de entierro y a los objetos ofrendados pudimos saber que este enterratorio correspondía al Período Formativo Temprano (Agüero et al. 1995).

Del mismo modo, una máquina retroexcavadora que realizaba trabajos correspondientes al tendido subterráneo de fibra óptica para una compañía telefónica, hacia el poniente de Quillagua, desenterró material arqueológico correspondiente al sitio Qui-37 (o Torre 203). Este sitio ya había sido identificado previamente por Gallardo y colaboradores (1993a) en sus prospecciones de comienzo de la década de 1990. La máquina despedazó varios entierros dejando al descubierto tres individuos adultos que se encontraban cubiertos con esteras de fibra vegetal, algunos cestos planos, gruesas mantas de lana, además de una bolsa chuspa, sandalias, botellas y tiestos de cerámica, todo lo cual indicaba que el cementerio también correspondía al Período Formativo (Agüero et al. 1995). Este descubrimiento también nos fue alertado por don Porfirio Vega.

Un tercer rescate fue llevado a cabo en el sitio Qui-84, objeto de estudio del último proyecto en curso, en donde un saqueo dejó expuesto un cuerpo de un individuo momificado envuelto en mantas felpudas. Cercano al individuo se encontraron restos de un gorro y algunos materiales líticos y fragmentos cerámicos. Las ofrendas del enterratorio habrían sido sustraídas y llevadas por los saqueadores (Agüero et al. 1995)

Todos los materiales obtenidos de estos rescates fueron depositados en el museo local -donde los objetos actualmente están siendo expuestosque cuenta con una importante colección y dos pequeñas salas de exhibición.

\section{Difusión del Conocimiento Arqueológico}

A partir de una práctica cada vez más frecuente, que se viene realizando en conjunto con los proyectos de investigación arqueológica en el Loa Superior y la cuenca del Salar de Atacama, liderados por Leonor Adán (FONDECYT 1940097) y Mauricio Uribe (FONDECYT 1970528 y 1000148), y en los que además varios de los autores han participado (Patricia Ayala, Carolina Agüero y Carlos Carrasco), en Quillagua se han llevado a cabo distintas actividades de difusión hacia la comunidad, tanto de los resultados de la investigación, como de las actividades llevadas a cabo por los arqueólogos, integrándonos con ésta, y a la vez comprometiendo a la misma en el conocimiento y protección de su patrimonio cultural.

Cabe señalar, que la comunidad de Quillagua no es indígena, o por lo menos no se encuentra registrada como tal en la institucionalidad representada por CONADI. Los miembros de esta comunidad se reconocen a sí mismos como "chilenos", y si bien tienen un reconocimiento a nivel histórico y mítico con los sitios arqueológicos, especialmente con los cementerios, a cuyos muertos llaman los "gentiles", no se sienten vinculados a estos en términos de parentesco. Los gentiles no son reconocidos como los abuelos, sino sólo como gentiles, es decir, personas que vivieron en tiempos pasados y a los que se les debe respeto.

No obstante, algunos estudios antropológicos han determinado que esta comunidad posee sus orígenes en poblaciones indígenas, vinculadas con las áreas de Tarapacá y Atacama. De este modo, varios de los vecinos quillagüinos reconocen haber llegado de niños o más adultos, desde localidades como Chela, Machuca, San Pedro de Atacama y Ollaguie, por el sector de Atacama, y de localida- 
des como Quehuita, cercanas a Pica, Guatacondo o Tamentica, en Tarapacá. Por ende, reconocen tener familiares en dichos lugares (Odone 1995).

También es preciso mencionar la particular ubicación geográfica de Quillagua, lo que ha determinado que esta localidad funcione como un cruce de caminos o como un punto de paso y de relaciones interregionales e interculturales. Así, hasta en tiempos históricos, Quillagua fue considerado como un nudo articulador de rutas desde donde se puede acceder a regiones tan distantes como Chiu-Chiu, Calama, Antofagasta, Tocopilla, y la desembocadura del río Loa entre muchas otras (Odone 1995).

Con este panorama social, y con la experiencia recogida en otros proyectos de la zona (p.ej. Loa Superior y Cuenca del Salar de Atacama), nuestro equipo de trabajo ha desarrollado diferentes actividades con la comunidad de manera que ésta ha ido poco a poco involucrándose con nuestro quehacer.

Dentro de dichas actividades destaca la realización de charlas en las que los investigadores responsables de estas investigaciones han informado a la comunidad sobre los planteamientos generales de los proyectos, a la vez que se han situado dichos problemas de investigación dentro del contexto de la prehistoria tanto del Norte Grande como de la localidad de Quillagua en particular. Estas sesiones se han llevado a cabo en la Escuela Pública Básica de Quillagua (la cual, además, nos alberga), en horarios posteriores a las jornadas diarias de terreno, y han sido abiertas a todo público. Por tanto, personas de todas las edades, desde niños a adultos mayores, han asistido a escuchar nuestra visión del pasado, y de los sitios arqueológicos y restos materiales con los cuales la comunidad convive diariamente.

Otra actividad informativa puesta en práctica por este equipo de trabajo, ha sido la de invitar a los alumnos de la escuela a jornadas de trabajo en terreno. Los alumnos, llevados por sus profesores, han podido ver en las excavaciones científicas cómo trabajan los arqueólogos.

Estas actividades son complementadas con asesorías recurrentes hacia los profesores, alumnos y cualquier miembro de la comunidad que lo requiera, en áreas de historia, ciencias sociales y computación. Además, las charlas y asistencias a terreno también han abordado temas como el Patrimonio Cultural y las diversas leyes de protección hacia el mismo, como la Ley de Impacto
Ambiental y la Ley de Monumentos Nacionales. Todas estas actividades nos obligan a usar un lenguaje fuera del ámbito académico y el que todos pueden entender acercando de esta manera la arqueología a la comunidad.

\section{Consideraciones Finales}

Con todo, creemos que la educación respecto del Patrimonio Cultural dirigida hacia personas que tengan o no una vinculación profesional (arqueólogos) o afectiva (comunidades indígenas) con éste, resulta importantísima para efectos de protección del mismo.

El caso de Quillagua resulta un ejemplo bastante claro, ya que el hecho de mantener una relación fluida entre arqueólogos y miembros de la comunidad, y una información de las actividades que realizan los primeros a la vez que un interés por parte de los segundos, sobre dichas actividades, compromete y vincula a estos últimos con el patrimonio. Así, ha sido la misma comunidad la que ha alertado a los arqueólogos sobre materiales culturales expuestos, ya sea de manera accidental o no, al sentirse capacitados para identificar un daño al patrimonio.

También creemos que este tipo de relaciones resulta bastante importante y útil no sólo para los arqueólogos, sino que también para la comunidad en términos de educación, información y protección del Patrimonio Cultural, y que no sólo debiera llevarse a cabo entre arqueólogos y comunidades indígenas, sino que entre arqueólogos y cualquier comunidad que conviva con tal patrimonio. De esta forma estaremos dando a nuestra disciplina una connotación social más abierta y más cercana a las personas, a la vez que estaremos educando sobre el "valor cultural" y no monetario que tiene el patrimonio cultural, lo que en definitiva se traduce en protección de éste, y más específicamente, de los sitios arqueológicos.

Agradecimientos: Quisiéramos agradecer a los organizadores del Encuentro por la invitación a participar, a la comunidad de Ollagüe por la hospitalidad, a la comunidad de Quillagua por recibirnos en cada temporada de trabajo en terreno, a todos nuestros compañeros que nos han apoyado en las distintas campañas, y a FONDECYT cuyo financiamiento ha permitido la investigación arqueológica en este valle. 


\section{Referencias citadas}

Agüero, C., M. Uribe y O. Reyes

1995 Nuevos sitios para la ocupación Formativa del valle de Quillagua. Boletín de la Sociedad Chilena de Arqueología 21:24- 27.

Agüero, C., M. Uribe, P. Ayala y B. Cases

1997 Variabilidad textil durante el Período Intermedio tardío en el valle de Quillagua: Una aproximación a la etnicidad. Estudios Atacameños 14:263-290.

1999 Una aproximación arqueológica a la etnicidad, y el rol de los textiles en la construcción de la identidad cultural en los cementerios de Quillagua (norte de Chile). Gaceta Arqueológica Andina 25:167-197.

Agüero, C., M. Uribe, C. Carrasco, J. González, I. Montt y

A. Valenzuela

2001 Excavaciones arqueológicas en el sitio 02-Qui-89 "Los Túmulos" de Quillagua, Loa Inferior (Norte grande de Chile). Informe de Avance Proyecto FONDECYT 1990168. Cervellino, M. y F. Téllez

1980 Emergencia y desarrollo de una aldea prehispánica de Quillagua, Antofagasta. Contribución Arqueológica 1:1-235.

Gallardo, F., L. Cornejo, R. Sánchez, B. Cases, A. Román y A. Deza

1993a Una aproximación a la cronología y el asentamiento en el oasis de Quillagua (río Loa, II región). Actas XII Con-

\section{Notas}

1 Cementerio Oriente (Qui-01) y Cementerio Poniente (Qui03).

2 No obstante, en vista de la enorme cantidad de material lítico cultural que se asociaba a los sitios asignables al Pe- greso Nacional de Arqueología Chilena Vol. 1: 41- 60. Temuco.

1993b Arqueología en el valle de Quillagua, río Loa, norte de Chile. Gaceta Arqueológica Andina 23:125-138.

Latcham, $\mathrm{R}$.

1933 Notas preliminares de un viaje arqueológico a la localidad de Quillagua. Revista Chilena de Historia y Geografía 34:130-138.

1938 La Arqueología de la Región Atacameña. Prensas de la Universidad de Chile, Santiago.

Núñez, L.

1965 Desarrollo cultural prehispánico del norte de Chile. Estudios Arqueológicos 1:37-106.

1968 Subárea Loa-costa chilena: Desde Copiapó a Pisagua. Actas del 37 Congreso Internacional de Americanistas, pp. 145-182. Mar del Plata.

1978 Northern Chile. En Chronologies in New World Archaeology, pp. 483-511. Academic Press, New York.

Odone, $\mathrm{C}$

1995 Quillagua: La descripción de un espacio desde la historia. Actas II Congreso Chileno de Antropología Vol. 2: 598-605. Valdivia.

ríodo Formativo, se determinó la realización de una Memoria de Título por parte del primer autor, que aborda el tema del material lítico, desarrollado en forma paralela al resto de la investigación. 